\title{
Solute Trapped at Defects during the Displacive Formation of Bainitic Ferrite
}

\author{
F.G. Caballero* and M. K. Miller** \\ * Centro Nacional de Investigaciones Metalúrgicas (CENIM-CSIC), Avda Gregorio del Amo, 8; \\ Madrid, E-28040, Spain \\ **Materials Science and Technology Division, Oak Ridge National Laboratory, PO Box 2008, \\ Oak Ridge, TN 37831-6136
}

New developments with bainite have resulted in a steel with an ultimate tensile strength of $2500 \mathrm{MPa}$, a hardness of 600-670 HV and a toughness in excess of 30-40 $\mathrm{MPa} \mathrm{m}^{1 / 2}$ [1]. The novel microstructure is generated in a high carbon $(0.98 \mathrm{wt} . \%)$ high silicon $(1.46 \mathrm{wt} . \%)$ steel austenitized for $15 \mathrm{~min}$. at $1000{ }^{\circ} \mathrm{C}$, and then isothermally transformed at temperatures of $\sim 200^{\circ} \mathrm{C}$. Iron does not diffuse during the transformation to bainite at this low temperature. As a result, 20-40 nm thick plates of ferrite are generated, giving rise to the exceptional properties. Extensive transmission electron microscopy of this microstructure has failed to reveal carbides within the bainitic ferrite. This is an interesting observation, since at these temperatures, steels with such high carbon levels should transform to a lower-bainitic microstructure. Similarly, analysis of X-ray diffraction results indicated that the carbon concentration in the bainitic ferrite was much higher than that expected from paraequilibrium thermodynamics between austenite and ferrite. This supersaturation is explained by the trapping of carbon at the dislocations in the bainitic ferrite. The relatively high dislocation density in bainite is attributed to the fact that shape deformation accompanying the displacive transformations is accommodated partially by plastic relaxation. The goal of this research is to evaluate the hypothesis of carbon trapping at dislocations within bainitic ferrite by atom probe tomography.

A carbon atom map obtained from the sample annealed at $200{ }^{\circ} \mathrm{C}$ for $48 \mathrm{~h}$ is shown in Fig. 1a. The carbon-enriched region (top-left) is austenite and the low carbon regions indicate the ferrite phase. The linear features with significant levels of carbon are dislocations in the vicinity of a ferrite/austenite interface. It is evident that dislocations trap the carbon atoms. The lateral extent of the Cottrell atmosphere in the vicinity of the dislocation was estimated from the envelope method [2] in terms of a radius of gyration to be $1_{\mathrm{g}}(\mathrm{x})=2.1 \mathrm{~nm}$ and $\mathrm{l}_{\mathrm{g}}(\mathrm{y})=2.5 \mathrm{~nm}$ (i.e., an extent of 5-6 nm). The average carbon level of the Cottrell atmosphere was estimated to be $7.4 \pm 0.1$ at. $\%$ C. The austenite adjacent to the bainitic ferrite also undergoes twinning deformation during bainite formation. The concentration profile in Fig. $1 \mathrm{~b}$ for a sample transformed at $300{ }^{\circ} \mathrm{C}$ for $4 \mathrm{~h}$ reveals a fine scale modulation normal to the parallel carbon-enriched regions of the carbon atom map. Thus, carbon may also segregate to microtwins in retained austenite (average carbon content of 5.3 at. \%). It is believed that solute segregation on defects associated with plastic relaxation in austenite, as those presented in Fig. 1, plays an important role on carbon redistribution during bainite transformation. Segregation at dislocations is expected to bind and hence prevent or impede the carbon atoms from diffusing out of the ferrite lattice. This explains the high level of carbon that exists in the bainitic ferrite after transformation and the small extent of carbon enrichment detected in the residual austenite.

Finally, carbon atom maps and concentration profiles of bainite at early stages of tempering $\left(400{ }^{\circ} \mathrm{C}\right.$ for $30 \mathrm{~min}$.) clearly show the presence of carbon-enriched regions, randomly dispersed throughout a carbon depleted ferrite matrix as presented in Fig. 2 . These clusters are $\sim 6 \mathrm{~nm}$ thick and have a maximum carbon content of $\sim 14$ at. \%. Such fluctuations of solute concentration may be associated with the solute redistribution to dislocations in bainite, as explained above. These 
regions may be gradually replaced by regions highly enriched in carbon, signifying the onset of epsilon carbide precipitation as the tempering temperature is increased. [3]

\section{References}

[1] F.G. Caballero and H.K.D.H. Bhadeshia. Curr. Opin. Solid St. M. 8 (2004) 251.

[2] M. K. Miller, Atom Probe Tomography, Kluwer Academic/Plenum Press, 2000, p. 158.

[3] Research at the Oak Ridge National Laboratory SHaRE User Facility was sponsored by the Office of Basic Energy Sciences, Division of Scientific User Facilities, U.S. Department of Energy, under contract DE-AC05-00OR22725 with UT-Battelle, LLC

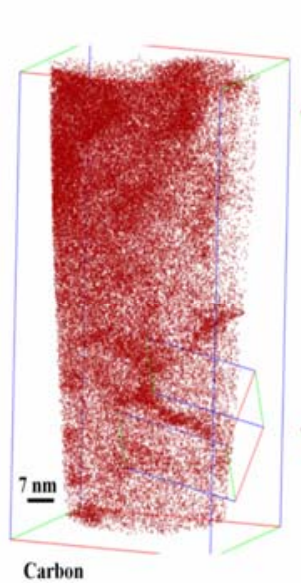

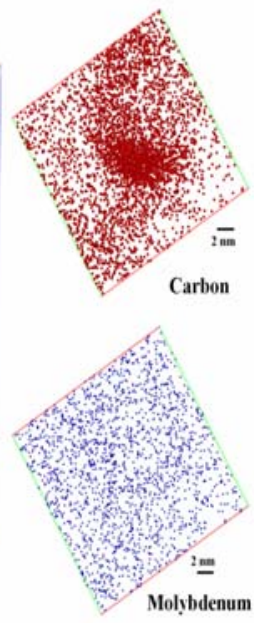

(a)

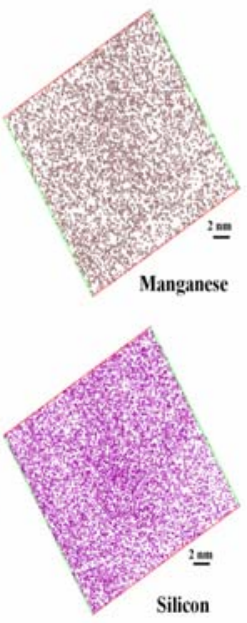

Silicon

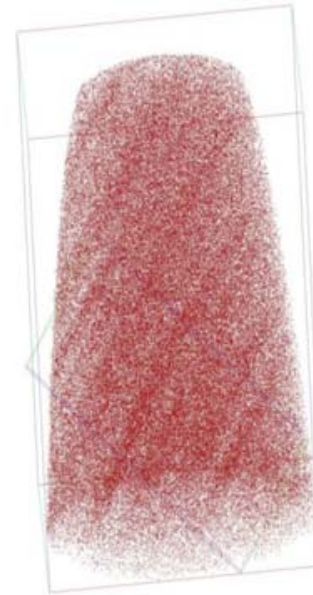

(b)

Figure 1. (a) Carbon atom map and projections showing carbon segregation at a dislocation in the vicinity of a ferrite/austenite interface in a sample transformed at $200{ }^{\circ} \mathrm{C}$ for $48 \mathrm{~h}$.; (b) Carbon atom map and concentration profile showing carbon segregation at microtwins in retained austenite for a sample transformed at $300{ }^{\circ} \mathrm{C}$ for $4 \mathrm{~h}$.

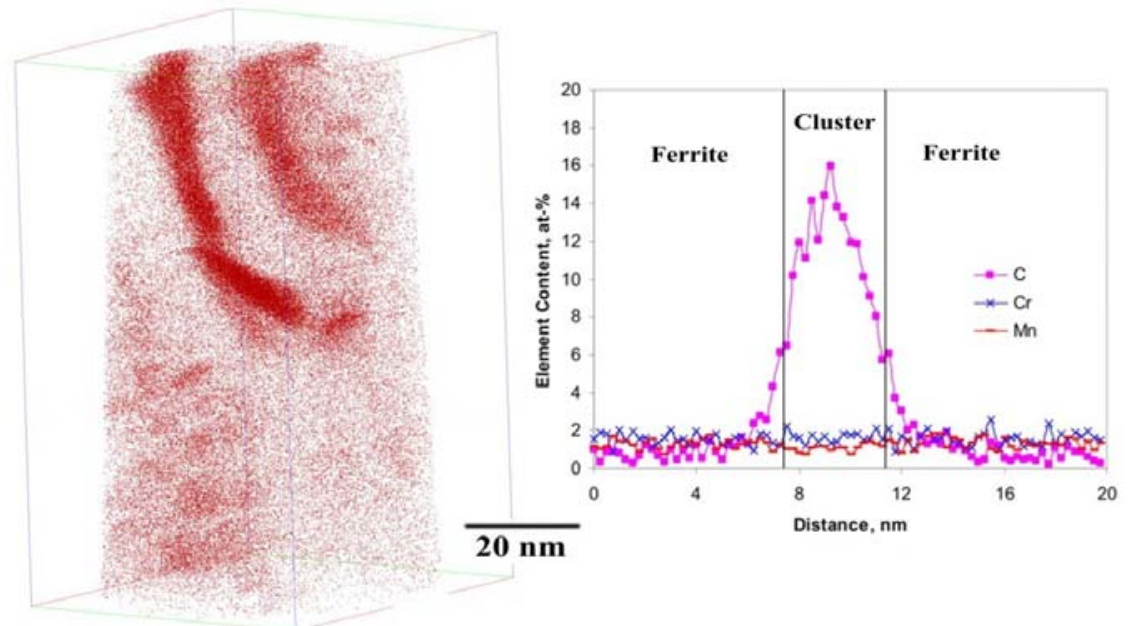

Figure 2.- Carbon atom map and concentration profile showing carbon clusters in bainitic ferrite after tempering at $400{ }^{\circ} \mathrm{C}$ for $30 \mathrm{~min}$. 